Article

\title{
Improving Mechanical Properties of $18 \%$ Mn TWIP Steels by Cold Rolling and Annealing
}

\author{
Vladimir Torganchuk, Andrey Belyakov* $*$ and Rustam Kaibyshev \\ Laboratory of Mechanical Properties of Nanostructured Materials and Superalloys, Belgorod State University, \\ Pobeda 85, Belgorod 308015, Russia \\ * Correspondence: belyakov@bsu.edu.ru; Tel.: +7-4722-585457
}

Received: 15 June 2019; Accepted: 10 July 2019; Published: 11 July 2019

\begin{abstract}
The microstructures and mechanical properties of Fe-0.4C-18Mn and Fe-0.6C-18Mn steels subjected to large strain cold rolling followed by annealing were studied. Cold rolling with a total reduction of $86 \%$ resulted in substantial strengthening at expense of plasticity. The yield strength and the ultimate tensile strength of above $1400 \mathrm{MPa}$ and $1600 \mathrm{MPa}$, respectively, were achieved in both steels, whereas total elongation decreased below $30 \%$. Subsequent annealing at temperatures above $600{ }^{\circ} \mathrm{C}$ was accompanied with the development of recrystallization leading to fine-grained microstructures with an average grain size of about $1 \mu \mathrm{m}$ in both steels. The fine-grained steels exhibited remarkable improved mechanical properties with a product of ultimate tensile strength by total elongation in the range of 50 to $70 \mathrm{GPa} \%$. The fine-grained steel with relatively high carbon content of $0.6 \% \mathrm{C}$ was characterized by ultimate tensile strength well above $1400 \mathrm{MPa}$ that was remarkably higher than that of about $1200 \mathrm{MPa}$ in the steel with $0.4 \% \mathrm{C}$.
\end{abstract}

Keywords: high-Mn steels; twinning induced plasticity; cold rolling; recrystallization annealing; grain refinement; strengthening

\section{Introduction}

High-Mn steels have aroused a great interest among material scientists and metallurgical engineers because of excellent mechanical performance [1]. These steels have a unique ability to strain hardening, which leads to extraordinary plasticity at room temperature [2-4]. The total elongation during standard tensile tests reaches $100 \%$. Such properties are provided by deformation twinning (i.e., twinning induced plasticity, TWIP effect) and/or deformation martensite (transformation induced plasticity, TRIP effect). Both TWIP and TRIP effects contribute to the hardening of the material during plastic flow, prevent the localization of deformation and increase plasticity. The main consumers of high-Mn steels with TRIP and TWIP effects are car manufacturers such as BMW, Porsche, etc. [5]. These materials are designed to provide a higher level of safety for drivers and passengers and to increase the overall efficiency of road transport. In addition, practical studies of high-Mn steels have recently launched in order to develop technologies for the production and use of such steels as damping elements for seismic resistant structures [6].

A combination of mechanical properties of high-Mn TWIP/TRIP steels depends on their alloying extent and microstructures [7,8]. Specific chemical composition including mainly $\mathrm{Mn}, \mathrm{C}, \mathrm{Al}$ and Si stabilizes austenite and provides appropriate stacking fault energy (SFE), which, in turn, results in TRIP (at SFE below about $20 \mathrm{~mJ} / \mathrm{m}^{2}$ ) or TWIP (at SFE of 20 to $50 \mathrm{~mJ} / \mathrm{m}^{2}$ ) effects [1,2]. Regarding the microstructure, it can be controlled by thermo-mechanical treatment involving warm to hot working $[9,10]$. Depending on application, desired level of strength and ductility of the steels can be obtained by rolling under appropriate conditions. A decrease in rolling temperature commonly promotes the strain hardening of steels with dynamically recrystallized and/or recovered 
microstructures [11]. A decrease in rolling temperature from 1100 to $500{ }^{\circ} \mathrm{C}$ has been shown to result in a significant increase in the yield strength of 18\%Mn steels from about 300-400 MPa to 850-950 $\mathrm{MPa}$, while ultimate tensile strength increased from 1000-1100 MPa to 1200-1300 MPa, whereas total elongation decreased to $30 \%$ [10]. The development of ultrafine grained microstructure in high-Mn TWIP steels through multiple primary recrystallization has been suggested as another promising method of steel processing [12]. A decrease in the recrystallized grain size provides strengthening without significant degradation of plasticity.

The aim of the present paper is to report our current studies on the microstructure and properties of advanced Fe-0.4C-18Mn and Fe-0.6C-18Mn steels processed by cold rolling followed by recrystallization annealing. It places particular emphasis on a comparison of the microstructures and properties obtained by dynamic recovery/recrystallization and static primary recrystallization. The properties of these steels with dynamically recovered/recrystallized microstructures depended remarkably on the carbon content [10]. Therefore, two steels with different carbon content were studied to reveal a possible solute effect on the mechanical properties of statically recrystallized steels.

\section{Materials and Methods}

Two high-Mn steels with different carbon content, i.e., Fe-18Mn-0.4C and Fe-18Mn-0.6C, were studied. The steels were produced by an induction melting. Then steel melts were hot rolled at $1150{ }^{\circ} \mathrm{C}$ with $60 \%$ reduction. The starting materials were characterized by uniform microstructures consisting of equiaxed grains with average sizes of $60 \mu \mathrm{m}$ and $50 \mu \mathrm{m}$ in Fe-18Mn-0.4C and Fe-18Mn-0.6C steels, respectively. The steel plates were subjected to rolling at ambient temperature to a total rolling reduction of $86 \%$. After each $15-20 \%$ reduction, the samples were subjected to intermediate recrystallization annealing at $700{ }^{\circ} \mathrm{C}$ for $30 \mathrm{~min}$. Following the last intermediate annealing, the final rolling reduction was $25 \%$ for both steels. Then, the rolled samples were annealed at temperatures of $500-800{ }^{\circ} \mathrm{C}$ for $30 \mathrm{~min}$.

The structural investigations were carried out on the sample sections normal to transverse direction (TD) using a Quanta 600 scanning electron microscope (SEM) (FEI, Hillsboro, OR, USA) equipped with an electron back scattering diffraction pattern (EBSD) analyzer incorporating an orientation imaging microscopy (OIM) system. The SEM specimens were electro-polished at a voltage of $20 \mathrm{~V}$ at room temperature using an electrolyte containing 10\% perchloric acid and $90 \%$ acetic acid. The OIM images were subjected to clean up procedure, setting the minimal confidence index of 0.1 , except cold rolled sample. In the latter case, the EBSD patterns with confidence index below 0.1 were omitted from the OIM analysis (these data-points appear as black spots in the OIM images). The OIM software (TSL OIM Analysis 6.2) (EDAX, Inc., Mahwah, NJ, USA) was used for evaluation of the mean grain size (D). The grain size was evaluated, counting all boundaries with misorientation of $\theta \geq 15^{\circ}$, including twin boundaries. The tensile tests were performed along the rolling direction at ambient temperature under a strain rate of $10^{-3} \mathrm{~s}^{-1}$ using an INSTRON 5882 on specimens with a gauge length of $12 \mathrm{~mm}$ and a cross section of $1.5 \mathrm{~mm} \times 3 \mathrm{~mm}$.

\section{Results and Discussion}

\subsection{Annealed Microstructures}

An example of cold rolled microstructure in Fe-0.4C-18Mn steel is presented in Figure 1a. The cold rolling results in significant strain hardening and makes the structural observation difficult, although highly elongated grains along the rolling direction (RD) can be recognized in Figure 1a. The cold rolled microstructure is commonly characterized by rather strong texture components close to brass and copper components (Figure 1b). Similar textures have been frequently observed in various face centered cubic (fcc) metals and alloys subjected to cold rolling [13]. 


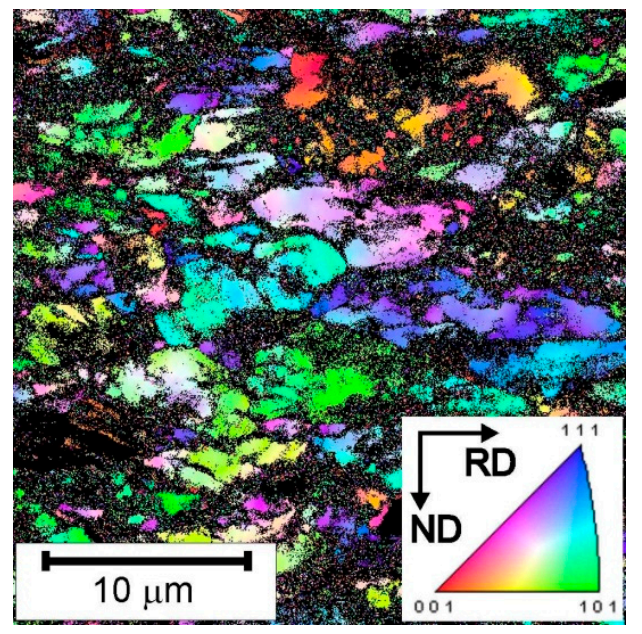

(a)

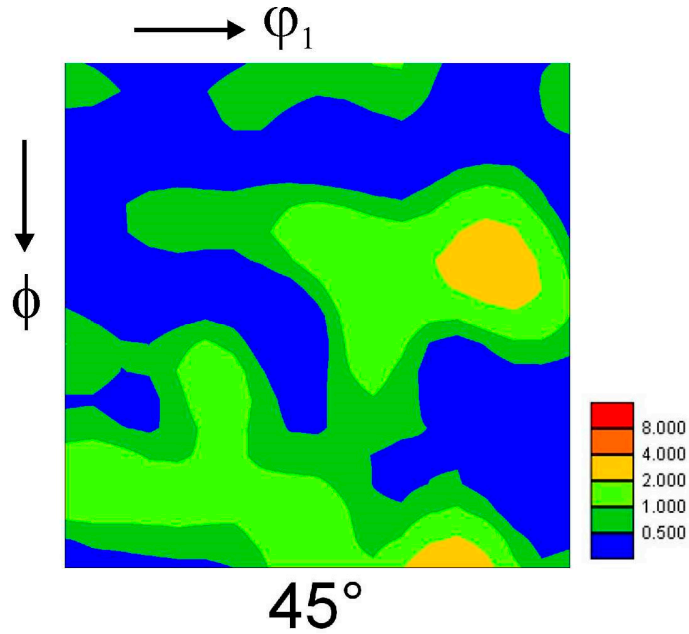

(b)

Figure 1. Microstructure (a) and orientation distribution function at $\phi_{2}=45^{\circ}$ (b) of an Fe- $0.4 \mathrm{C}-18 \mathrm{Mn}$ steel subjected to cold rolling. Colors in (a) correspond to crystallographic direction along the normal direction (ND).

Annealing softening is shown in Figure 2 as a temperature dependence of hardness. Both steels are characterized by almost the same change in the hardness during annealing. Namely, an increase in annealing temperature to $550{ }^{\circ} \mathrm{C}$ leads to gradual decrease in the hardness. The hardness decrease after annealing at $550^{\circ} \mathrm{C}$ is about $10 \%$ and can be attributed to static recovery leading to a sluggish softening. A drastic decrease in the hardness takes place as temperature increases to $650{ }^{\circ} \mathrm{C}$ followed by slow softening upon further increase in temperature. It can be concluded, therefore, that temperature of around $600{ }^{\circ} \mathrm{C}$ corresponds to recrystallization temperature of the present steels much similar to other studies on primary recrystallization in high-Mn TWIP steels [14].

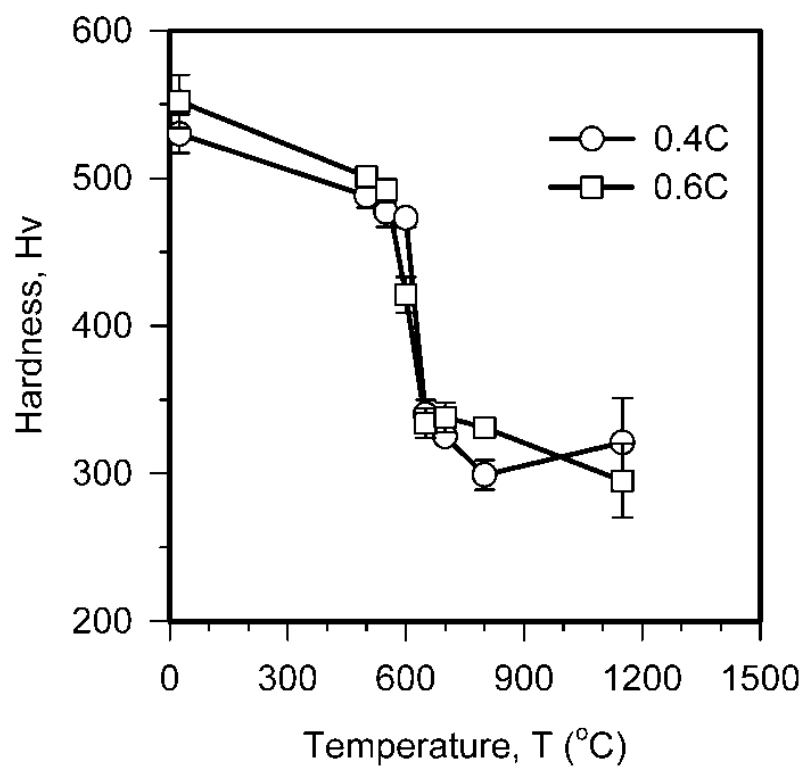

Figure 2. Effect of annealing temperature on hardness of Fe- $0.4 \mathrm{C}-18 \mathrm{Mn}$ and Fe-0.6C-18Mn steels $(0.4 \mathrm{C}$ and $0.6 \mathrm{C}$, respectively) subjected to cold rolling.

Typical annealed microstructures evolved in Fe-0.4C-18Mn and Fe-0.6C-18Mn steel samples after annealing at $600{ }^{\circ} \mathrm{C}$ or $650{ }^{\circ} \mathrm{C}$ are shown in Figure 3. Some parameters of the annealed microstructures 
are listed in Table 1. The annealed microstructures consist of almost equiaxed grains with a grain size of about $1 \mu \mathrm{m}$ irrespective of carbon content and annealing temperature. Numerous $\Sigma 3$ CSL (coincident site lattice) boundaries corresponding to annealing twins testify to discontinuous recrystallization involving grain nucleation and growth as the main mechanism of microstructure evolution during the present treatment. On the other hand, frequently serrated grain boundaries suggest that the recrystallization processes have not completed. Hence, relatively high strength owing to residual stresses can be expected in these steel samples.
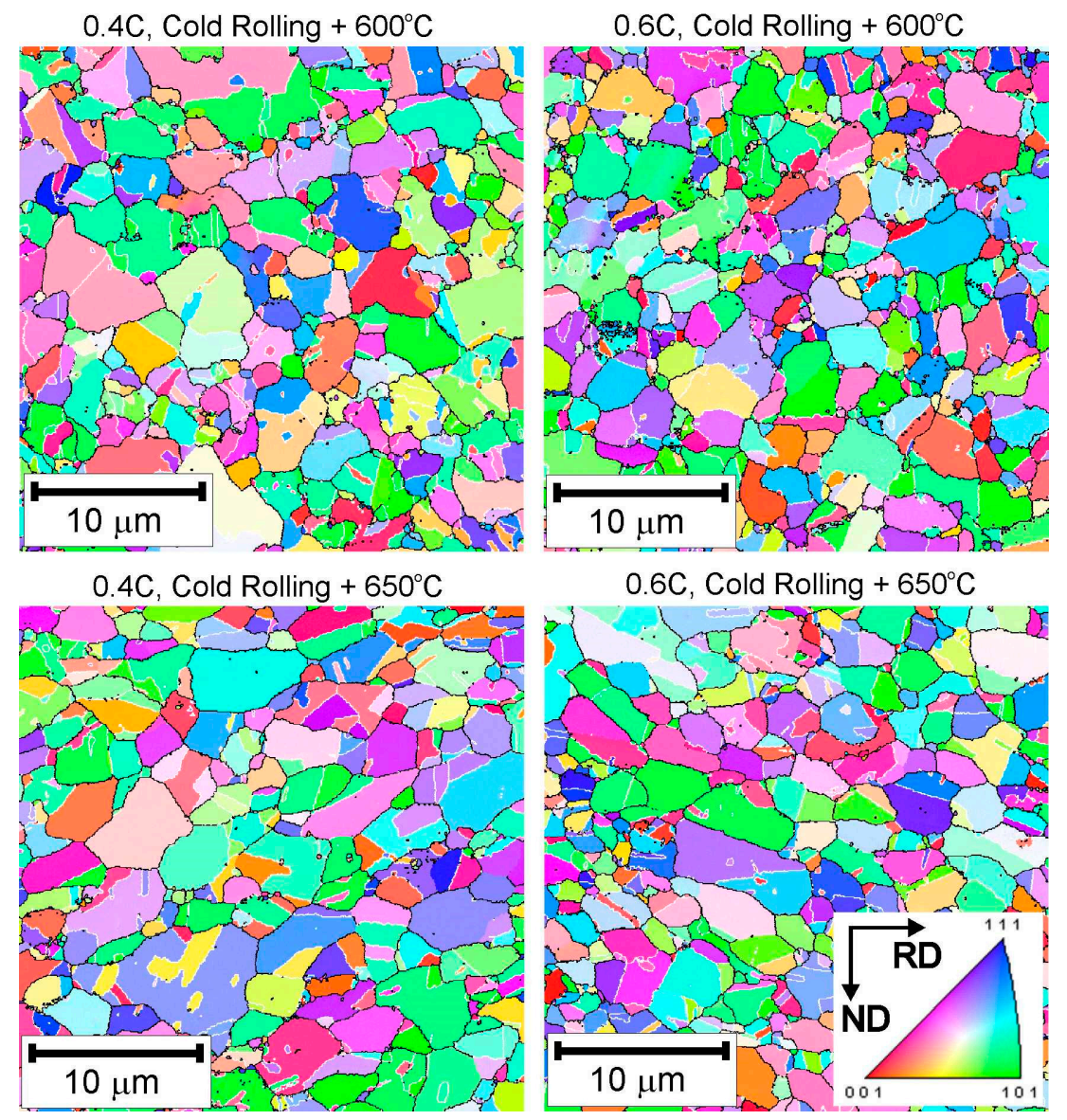

Figure 3. Typical microstructures in Fe- $0.4 \mathrm{C}-18 \mathrm{Mn}$ and Fe-0.6C-18Mn steels ( $0.4 \mathrm{C}$ and $0.6 \mathrm{C}$, respectively) subjected to cold rolling and annealing at indicated temperatures. High-angle grain boundaries and $\Sigma 3$ CSL boundaries are indicated by the black and white lines, respectively. The colors correspond to crystallographic direction along ND.

Table 1. Some parameters of the annealed microstructures.

\begin{tabular}{cccc}
\hline Steel Processing & Grain Size, $\mu \mathrm{m}$ & $\begin{array}{c}\text { Fraction of } \Sigma 3 \mathrm{CSL} \\
\text { Boundaries }\end{array}$ & $\begin{array}{c}\text { Fraction of Low-Angle } \\
\text { Boundaries }\end{array}$ \\
\hline $\begin{array}{c}\text { Fe-0.4C-18Mn } \\
\text { Cold Rolling }+600^{\circ} \mathrm{C} \\
\text { Fe-0.4C-18Mn } \\
\begin{array}{c}\text { Cold Rolling }+650^{\circ} \mathrm{C} \\
\text { Fe-0.6C-18Mn }\end{array}\end{array}$ & 1.07 & 0.40 & 0.06 \\
$\begin{array}{c}\text { Cold Rolling }+600^{\circ} \mathrm{C} \\
\text { Fe-0.6C-18Mn }\end{array}$ & 1.10 & 0.39 & 0.07 \\
Cold Rolling $+650^{\circ} \mathrm{C}$ & 1.03 & 0.29 & 0.10 \\
\hline
\end{tabular}


Corresponding grain boundary misorientation distributions are shown in Figure 4. Commonly, the misorientation distributions are characterized by a high peak against large misorientations of around $60^{\circ}$. This maximum corresponds to annealing twin boundaries, which frequently develop in fcc-metallic materials with low SFE during static recrystallization [15]. The misorientation distribution of other high-angle boundaries looks like a random one (indicated by the dotted line in Figure 4) with a broad peak at $45^{\circ}$ [16]. The most interesting feature of the obtained microstructures is a relatively large fraction of low-angle subboundaries. Besides the sharp peak of twin boundaries, all misorientation distributions in Figure 4 exhibit small peaks corresponding to low-angle subboundaries. This is unusual for discontinuous static (primary) recrystallization [17]. The low-angle subboundaries in the annealed samples might remain from dislocation substructures produced by cold rolling. Again, the presence of dislocation subboundaries in the annealed samples implies incomplete softening. The largest fraction of low-angle subboundaries is observed in the Fe-0.6C-18Mn steel samples after annealing at $600{ }^{\circ} \mathrm{C}$, suggesting a relatively high strength for this condition.

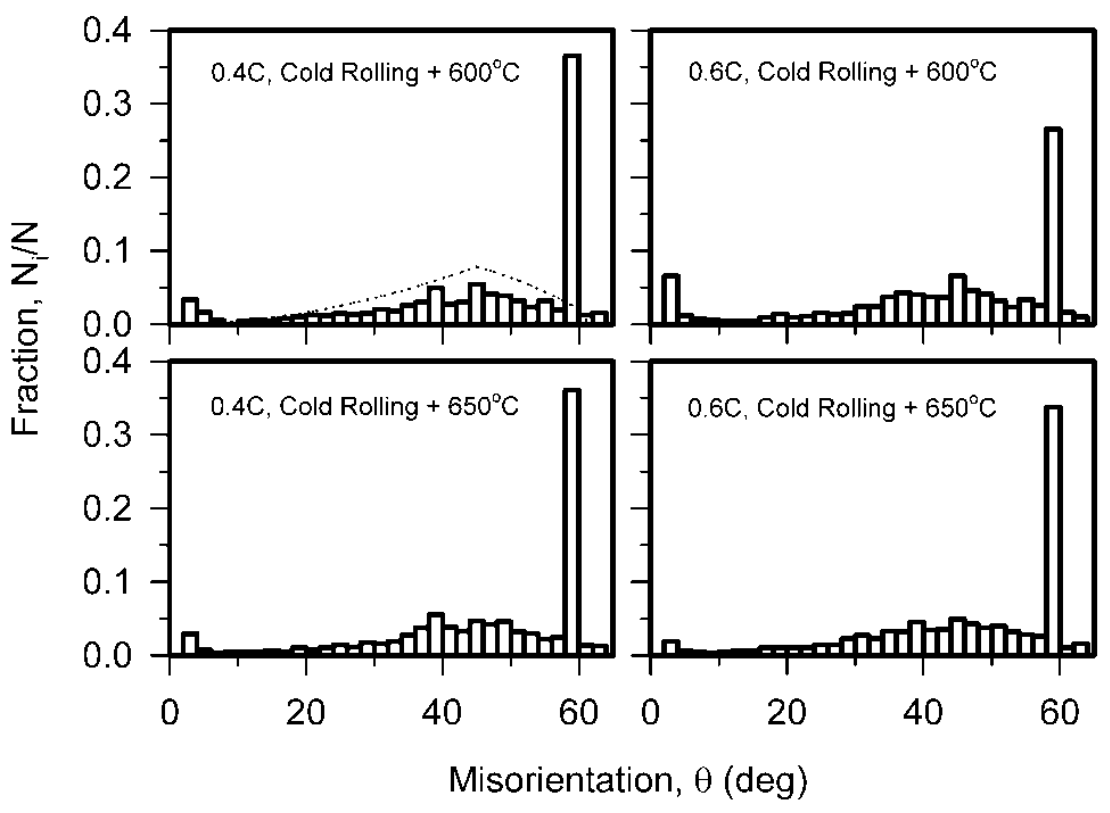

Figure 4. Grain/subgrain boundary misorientation distribution in Fe-0.4C-18Mn and Fe-0.6C-18Mn steels $(0.4 \mathrm{C}$ and $0.6 \mathrm{C}$, respectively) subjected to cold rolling and annealing at indicated temperatures. The dotted line indicates random misorientation distribution.

The development of discontinuous static recrystallization usually weakens the textures caused by previous cold rolling. Figure 5 shows orientation distribution functions at sections of $\phi_{2}=45^{\circ}$ for the studied annealed steel samples. As could be expected, the annealed samples do not exhibit any strong textures. The annealed textures include orientations close to Brass and Copper components. The latter is more pronounced in the Fe- $0.4 \mathrm{C}-18 \mathrm{Mn}$ steel samples, especially, after annealing at $650{ }^{\circ} \mathrm{C}$. It should be noted that similar texture components were observed in the cold rolled samples (Figure 1b). The annealed textures, therefore, may correspond to early stage of recrystallization, when the deformation microstructures have not been completely replaced by the annealed ones. 


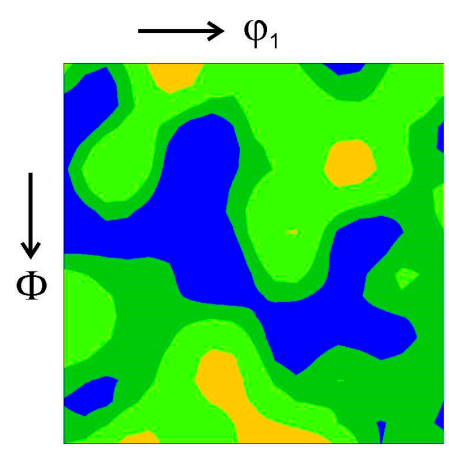

$0.4 \mathrm{C}$, Cold Rolling $+600^{\circ} \mathrm{C}$

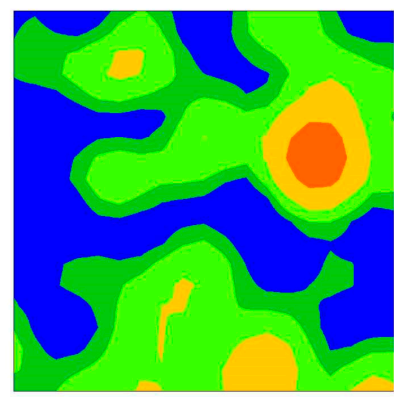

$0.4 \mathrm{C}$, Cold Rolling $+650^{\circ} \mathrm{C}$

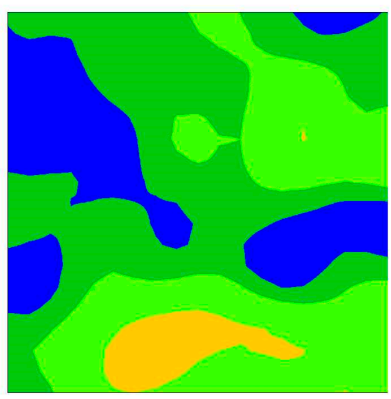

$0.6 \mathrm{C}$, Cold Rolling $+600^{\circ} \mathrm{C}$

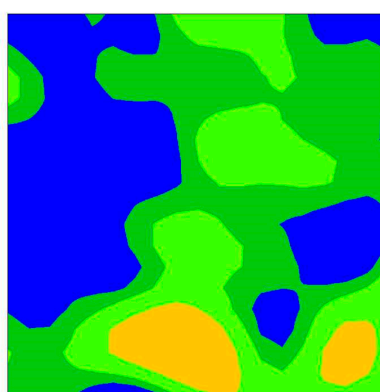

$0.6 \mathrm{C}$, Cold Rolling $+650^{\circ} \mathrm{C}$

Figure 5. Orientation distribution functions at $\phi_{2}=45^{\circ}$ for Fe- $0.4 \mathrm{C}-18 \mathrm{Mn}$ and Fe- $0.6 \mathrm{C}-18 \mathrm{Mn}$ steels $(0.4 \mathrm{C}$ and $0.6 \mathrm{C}$, respectively) subjected to cold rolling and annealing at indicated temperatures.

\subsection{Tensile Behaviour}

A series of engineering stress-elongation curves obtained during tensile tests of the cold rolled and annealed steel samples with fine-grained microstructures is shown in Figure 6. The values of yield strength $\left(\sigma_{0.2}\right)$, ultimate tensile strength (UTS) and total elongation $(\delta)$ are represented in Table 2 . The cold rolling resulted in significant strengthening. The yield strength above $1400 \mathrm{MPa}$ and UTS above $1600 \mathrm{MPa}$ is obtained in both Fe-0.4C-18Mn and Fe-0.6C-18Mn steels after cold rolling. On the other hand, total elongation of the cold rolled samples does not exceed $30 \%$. Recrystallization annealing at $600-650{ }^{\circ} \mathrm{C}$ substantially improves plasticity. Total elongation of $40-60 \%$ is obtained after annealing. It should be noted that such enhancement of plasticity is not accompanied by a complete softening. The yield strength remains at a level of about $500 \mathrm{MPa}$ in the Fe- $0.4 \mathrm{C}-18 \mathrm{Mn}$ steel samples after annealing and that of about $700 \mathrm{MPa}$ and $1000 \mathrm{MPa}$ is obtained in Fe-0.6C-18Mn steel after annealing at $650^{\circ} \mathrm{C}$ and $600{ }^{\circ} \mathrm{C}$, respectively. The annealed samples exhibit pronounced strain hardening. Following yielding, the stress gradually increases up to maximum followed by failure, i.e., total and uniform elongations are almost the same, which is typical of high-Mn TWIP steels [1,7-10]. Therefore, the development of fine-grained microstructures by cold rolling and annealing results in beneficial combination of high strength and plasticity in the present steels. Some serrations on the stress-elongation curves testify to dynamic strain aging, which has been frequently observed in high-manganese steels $[1,3,7]$. 


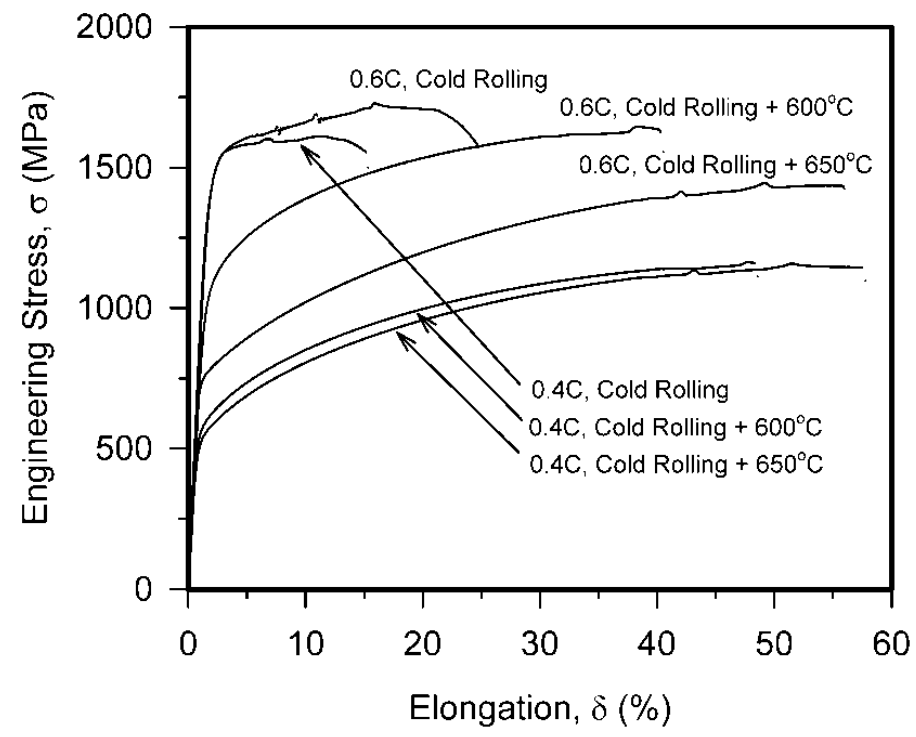

Figure 6. Engineering stress-elongation curves of Fe-0.4C-18Mn and Fe-0.6C-18Mn steels (0.4C and $0.6 \mathrm{C}$, respectively) subjected to cold rolling and annealing at indicated temperatures.

Table 2. The yield strength $\left(\sigma_{0.2}\right)$, ultimate tensile strength (UTS) and total elongation $(\delta)$.

\begin{tabular}{|c|c|c|c|}
\hline Steel Processing & $\sigma_{0.2}, \mathrm{MPa}$ & UTS, MPa & $\delta, \%$ \\
\hline $\begin{array}{c}\text { Fe-0.4C-18Mn } \\
\text { Cold Rolling }+600{ }^{\circ} \mathrm{C}\end{array}$ & 530 & 1165 & 45 \\
\hline $\begin{array}{l}\text { Fe- } 0.4 \mathrm{C}-18 \mathrm{Mn} \\
\text { Cold Rolling }+650{ }^{\circ} \mathrm{C}\end{array}$ & 465 & 1155 & 55 \\
\hline $\begin{array}{c}\text { Fe-0.6C-18Mn } \\
\text { Cold Rolling }+600{ }^{\circ} \mathrm{C}\end{array}$ & 1000 & 1650 & 40 \\
\hline $\begin{array}{c}\text { Fe-0.6C-18Mn } \\
\text { Cold Rolling }+650^{\circ} \mathrm{C}\end{array}$ & 730 & 1445 & 55 \\
\hline
\end{tabular}

The strengthening by grain refinement is generally discussed in terms of the Hall-Petch relationship $[18,19]$. The relationship between the grain size and the yield strength of the present steel samples after annealing is shown in Figure 7a along with results obtained by warm to hot rolling of the same steels [10]. The hot rolled samples were characterized by dynamically recrystallized microstructures. Corresponding yield strength can be expressed by Hall-Petch-type relationship. In contrast, warm rolled microstructures were affected by dynamic recovery only and, thus, contained high dislocation densities. In this case, the yield strengths appear well above those predicted by Hall-Petch-type relationship in Figure 7a because of additional strengthening caused by relatively high dislocation density in recovered microstructures. It is interesting to note that the yield strength of the annealed Fe-0.4C-18Mn steel samples roughly corresponds to that predicted by Hall-Petch-type relationship, whereas the Fe-0.6C-18Mn steel samples exhibit remarkably higher yield strength, which is comparable with that of warm rolled steel samples. This strengthening can be attributed to remained work hardening in the steel samples with relatively high carbon content as suggested by microstructural investigations, e.g., large fraction of low-angle dislocation subboundaries in Figure 4. The low-angle dislocation subboundaries resulted from recovery, namely, polygonization. In contrast to recrystallization, which requires incubation period, recovery processes develop just upon heating and lead to partial release of deformation stored energy owing to dislocation rearrangement and annihilation [17]. Partial softening by recovery reduces the driving pressure for recrystallization development. Therefore, recovered portions of microstructure may coexist with recrystallized ones for rather long time, especially during annealing at relatively low temperatures, when diffusion processes 
are slowed down. The remained recovered portions are characterized by higher dislocation densities as compared to perfect recrystallized grains and, thus, may provide an additional strengthening.

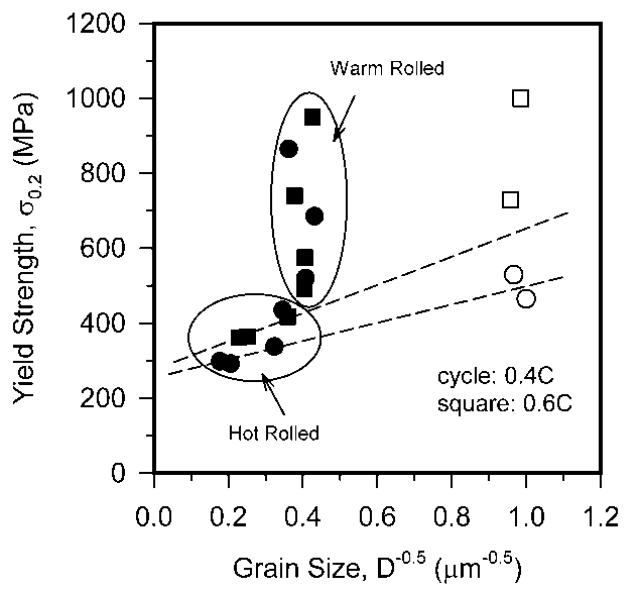

(a)

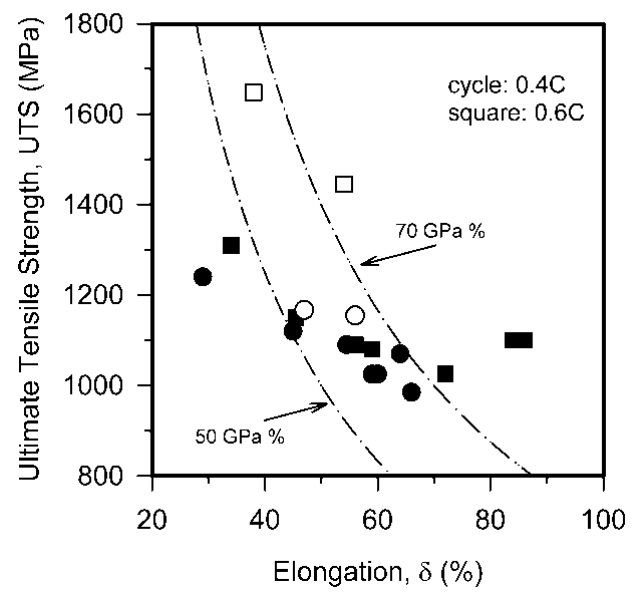

(b)

Figure 7. Relationship between the grain size and the yield strength (a) and the ultimate tensile strength and elongation (b) for Fe-0.4C-18Mn and Fe-0.6C-18Mn steels ( $0.4 \mathrm{C}$ and $0.6 \mathrm{C}$, respectively) processed by warm to hot rolling (filled symbols [10]) and cold rolling followed by annealing (open symbols, present study).

The present annealed samples demonstrate improved combination of strength and plasticity as represented by a product of UTS by total elongation in Figure 7b. The values of UTS $\times \delta$ in the range of $50 \mathrm{GPa}$ to $70 \mathrm{GPa}$ are obtained in the present samples. The larger values correspond to the samples annealed at higher temperature, when annealing softening is compensated by increasing ductility. It should be noted that the Fe- $0.4 \mathrm{C}-18 \mathrm{Mn}$ steel samples exhibit almost the same level of mechanical properties as obtained by warm to hot rolling [10]. In contrast, the steel with relatively high carbon content of $0.6 \%$ displays remarkably higher strength for the same plasticity after cold rolling followed by annealing.

\section{Conclusions}

The microstructures and mechanical properties of Fe-0.4C-18Mn and Fe-0.6C-18Mn steels subjected to large strain cold rolling followed by annealing were studied. The main results can be summarized as follows.

Cold rolling with a total reduction of $86 \%$ resulted in substantial strengthening. The yield strength above $1400 \mathrm{MPa}$ and ultimate tensile strength above $1600 \mathrm{MPa}$ were achieved in the both steels after cold rolling. On the other hand, corresponding total elongation did not exceed $30 \%$.

Subsequent annealing at temperatures above $600^{\circ} \mathrm{C}$ was accompanied with the recrystallization development resulting in the fine-grained microstructures with an average grain size of about $1 \mu \mathrm{m}$ in the both steels.

The fine-grained steels processed by cold rolling and annealing exhibited beneficial combination of high strength and plasticity. The product of ultimate tensile strength by total elongation comprised 50 to $70 \mathrm{GPa} \%$ depending on carbon content and processing conditions.

Author Contributions: Conceptualization, V.T. and R.K.; methodology, V.T.; validation, V.T., formal analysis, A.B.; investigation, V.T.; writing—original draft preparation, V.T.; writing—review and editing, A.B.; supervision, R.K.; funding acquisition, A.B.

Funding: This research was funded by the Ministry of Education and Science, Russia, under Grant No. 11.3719.2017/PCh (11.3719.2017/4.6). 
Conflicts of Interest: The authors declare no conflict of interest.

\section{References}

1. Bouaziz, O.; Allain, S.; Scott, C.P.; Cugy, P.; Barbier, D. High Manganese Austenitic Twinning Induced Plasticity Steels: A Review of the Microstructure Properties Relationships. Curr. Opin. Solid State Mater. Sci. 2011, 15, 141-168. [CrossRef]

2. Saeed-Akbari, A.; Mosecker, L.; Schwedt, A.; Bleck, W. Characterization and Prediction of Flow Behavior in High-Manganese Twinning Induced Plasticity Steels: Part I. Mechanism Maps and Work-Hardening Behavior. Metall. Mater. Trans. A 2012, 43, 1688-1704. [CrossRef]

3. Sevsek, S.; Brasche, F.; Haase, C.; Bleck, W. Combined deformation twinning and short-range ordering causes serrated flow in high-manganese steels. Mater. Sci. Eng. A 2019, 746, 434-442. [CrossRef]

4. Song, W.; Ingendahl, T.; Bleck, W. Control of Strain Hardening Behavior in High-Mn Austenitic Steels. Acta Metall. Sin. Engl. Lett. 2014, 27, 546-556. [CrossRef]

5. Keeler, S.; Kimchi, M. Advanced High-Strength Steels Application Guidelines V5; WorldAutoSteel: Middletown, OH, USA, 2014.

6. Nikulin, I.; Sawaguchi, T.; Kushibe, A.; Inoue, Y.; Otsuka, H.; Tsuzaki, K. Effect of strain amplitude on the low-cycle fatigue behavior of a new Fe-15Mn-10Cr-8Ni-4Si seismic damping alloy. Int. J. Fatigue 2016, 88, 132-141. [CrossRef]

7. Kusakin, P.S.; Kaibyshev, R.O. High-Mn twinning-induced plasticity steels: Microstructure and mechanical properties. Rev. Adv. Mater. Sci. 2016, 44, 326-360.

8. De Cooman, B.C.; Estrin, Y.; Kim, S.K. Twinning-induced plasticity (TWIP) steels. Acta Mater. 2018, 142, 283-362. [CrossRef]

9. Kusakin, P.; Tsuzaki, K.; Molodov, D.A.; Kaibyshev, R.; Belyakov, A. Advanced thermomechanical processing for a high-Mn austenitic steel. Metall. Mater. Trans. A 2016, 47, 5704-5708. [CrossRef]

10. Torganchuk, V.; Belyakov, A.; Kaibyshev, R. Effect of rolling temperature on microstructure and mechanical properties of 18\%Mn TWIP/TRIP steels. Mater. Sci. Eng. A 2017, A708, 110-117. [CrossRef]

11. Sakai, T.; Belyakov, A.; Kaibyshev, R.; Miura, H.; Jonas, J.J. Dynamic and post-dynamic recrystallization under hot, cold and severe plastic deformation conditions. Prog. Mater. Sci. 2014, 60, 130-207. [CrossRef]

12. Saha, R.; Ueji, R.; Tsuji, N. Fully recrystallized nanostructure fabricated without severe plastic deformation in high-Mn austenitic steel. Scripta Mater. 2013, 68, 813-816. [CrossRef]

13. Hirsch, J.; Lucke, K. Mechanism of deformation and development of rolling texture in polycrystalline f.c.c. metal-I. Description of rolling texture development in homogeneous CuZn alloys. Acta Metall. Mater. 1988, 36, 2863-2882. [CrossRef]

14. Yanushkevich, Z.; Belyakov, A.; Kaibyshev, R.; Haase, C.; Molodov, D.A. Effect of cold rolling on recrystallization and tensile behavior of a high-Mn steel. Mater. Charact. 2016, 112, 180-187. [CrossRef]

15. Mahajan, S. Critique of mechanisms of formation of deformation, annealing and growth twins: Face-centered cubic metals and alloys. Scripta Mater. 2013, 68, 95-99. [CrossRef]

16. Mackenzie, J.K. Second Paper on the Statistics Associated with the Random Disorientation of Cubes. Biometrika 1958, 45, 229-240. [CrossRef]

17. Humphreys, F.J.; Hatherly, M. Recrystallization and Related Annealing Phenomena, 2nd ed.; Elsevier: Oxford, UK, 2004; pp. 215-268. ISBN 0-08-044164-5.

18. Hall, E.O. The deformation and ageing of mild steel: III discussion of results. Proc. R. Soc. Lond. Ser. B 1951, 64, 747-753. [CrossRef]

19. Petch, N.J. The cleavage strength of polycrystals. J. Iron Steel Inst. 1953, 174, 25-28.

(C) 2019 by the authors. Licensee MDPI, Basel, Switzerland. This article is an open access article distributed under the terms and conditions of the Creative Commons Attribution (CC BY) license (http://creativecommons.org/licenses/by/4.0/). 